\title{
Mainstreaming and scaling up the Kenya Adolescent Reproductive Health Project
}

\author{
lan Askew \\ Population Council \\ Humphres Evelia \\ Population Council
}

Follow this and additional works at: https://knowledgecommons.popcouncil.org/departments_sbsr-rh

Part of the Community Health and Preventive Medicine Commons, Demography, Population, and Ecology Commons, Family, Life Course, and Society Commons, Health Services Research Commons, International Public Health Commons, and the Medicine and Health Commons How does access to this work benefit you? Let us know!

\section{Recommended Citation}

Askew, lan and Humphres Evelia. 2007. "Mainstreaming and scaling up the Kenya Adolescent Reproductive Health Project," FRONTIERS Report. Nairobi: Population Council. 


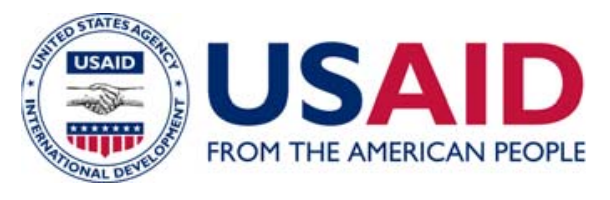

\section{(P) Population Council \\ FRONTIERS}

\section{Mainstreaming and Scaling Up the Kenya Adolescent Reproductive Health Project}

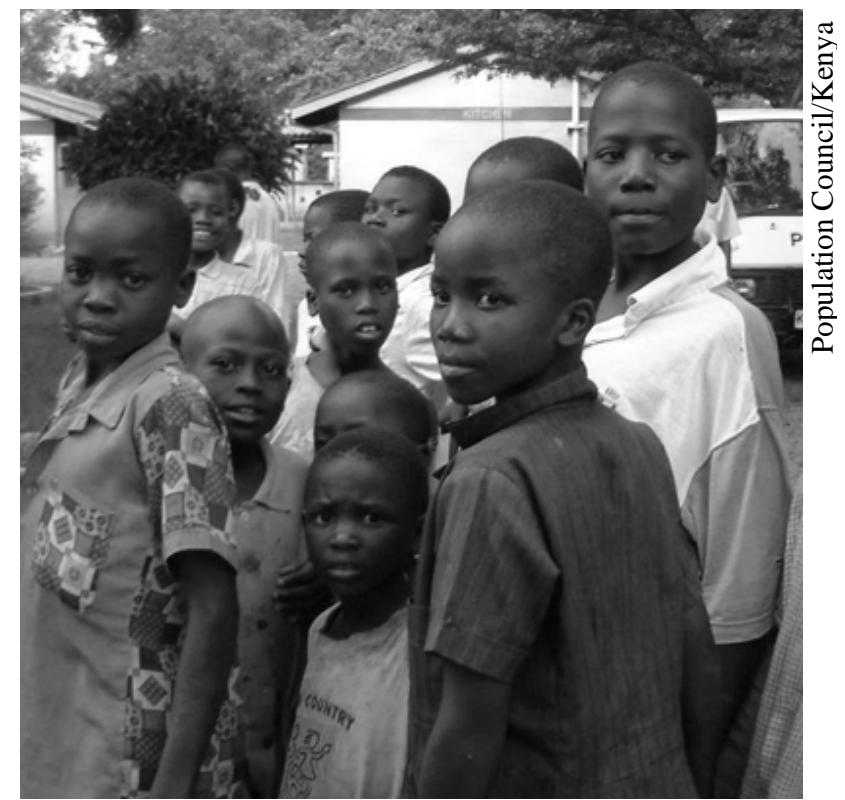

Youth outside district health center, Busia, Kenya

\section{Ian Askew and Humphres Evelia \\ Population Council. \\ Frontiers in Reproductive Health Program}

March 2007

This publication is made possible by the generous support of the American people through the United States Agency for International Development (USAID) under the terms of Cooperative Agreement No. HRN-A-00-98-00012-00. The contents are the responsibility of the FRONTIERS Program and do not necessarily reflect the views of USAID or the United States Government 


\section{Background}

From 1999-2003, FRONTIERS implemented a Global Agenda program of operations research (OR) projects to address the reproductive health $(\mathrm{RH})$ needs of adolescents in four countriesBangladesh, Kenya, Mexico, and Senegal. The project was implemented in two districts of Western Province in Kenya, and was known as the Kenya Adolescent Reproductive Health Project (KARHP) ${ }^{1}$. The project supported a public sector, multisectoral intervention to enhance young people's knowledge and behaviour regarding reproductive health and HIV prevention, and systematically tested its feasibility, acceptability, effectiveness and cost. This OR project, implemented jointly with PATH, demonstrated that such a multisectoral intervention could be implemented by the public sector, was acceptable to communities, its effect in influencing reproductive health and HIV/AIDS knowledge, attitudes and behaviour was understood, and the type and amount of financial and other resources needed to implement each of the component activities was calculated.

The pilot project showed that it was possible to reach $50 \%$ of the adult population (over 7,200$)$ and over two-thirds of all 10-19 year olds, in and out of school (over 30,000) living in the project area, through supporting three Government of Kenya ministries: Ministry of Education, Science and Technology (MOEST); Ministry of Gender, Sports, Culture and Social Services (MGSCSS); and Ministry of Health (MOH). FRONTIERS and PATH subsequently undertook a broad and systematic dissemination of the findings and their programmatic, financial and policy implications. Dissemination included the communities where the study was implemented, district level ministry staff, and national-level stakeholders in the three ministries and other interested organizations. These activities were completed by April 2003.

Underlying the strategy of working directly with the existing structures and staff of the three ministries was the expectation that this approach would facilitate incorporation of effective reproductive health (RH) and HIV prevention components into each ministry's routine operating procedures, with minimal disruption or additional resource requirements. Through their continual engagement in the project at the community, location, district, provincial and national levels, the three ministries have shown their commitment to the institutionalization of these activities so that they can be sustained within their routine work plans and budgets.

Given the success of the KARHP pilot activities, and the initial expressions of interest by the communities and all three ministries in incorporating them into their routine operations, a followon project was initiated for the period August 2003 to April 2005 with support from

USAID/Kenya. This project sought to facilitate the process of "adapting and institutionalizing” the reproductive health and HIV activities within the three ministries at the district level initially, and to create conditions for their replication in other districts, and ultimately in other provinces.

\footnotetext{
${ }^{1}$ Askew, Ian, Jane Chege, Carolyne Njue, and Samson Radeny. 2004. “A multi-sectoral approach to providing reproductive health information and services to young people in Western Kenya: The Kenya adolescent reproductive health project," FRONTIERS Final Report. Washington, DC: Population Council. http://www.popcouncil.org/pdfs/frontiers/FR_FinalReports/Kenya_KARP\%20Adol.pdf
} 
The specific aims of the follow-on project were to:

1. Assist the three ministries to institutionalize those KARHP strategies and services proven cost-effective within the study locations by:

a. Identifying an adolescent reproductive health and HIV intervention package of costeffective activities from within the comprehensive set of activities tested through KARHP that the relevant ministries feel can feasibly be implemented as routine activities.

b. Developing operational protocols for implementing the intervention package through each ministry's local and district level systems.

c. Building the technical capacity of ministry staff in the two intervention districts to sustain implementation of the adolescent reproductive health and HIV intervention package in the four experimental locations and to introduce the intervention package into the two control locations.

d. Developing operational annual budgets that cover the full cost of implementing the adolescent reproductive health and HIV intervention package at the location level.

2. Assist the three ministries to replicate the adolescent reproductive health and HIV intervention package throughout the two districts and in the six other districts of Western Province by:

a. Assisting the three ministries to introduce the intervention packages in all remaining locations in the two districts.

b. Building the capacity of staff of the three ministries in the six other districts in Western Province to plan, budget, finance and implement the intervention package.

3. Document systematically and disseminate widely the lessons learned in sustaining, scaling up, and replicating successful adolescent reproductive health and HIV interventions to other provinces and districts in Kenya.

4. Assist the three ministries to review their policies, standards, and guidelines concerning adolescent reproductive health and HIV prevention and, if necessary, to revise them accordingly. 
During this follow-on "institutionalization" period, over 1,100 people were trained across the three ministries as implementers of KARHP activities:

MOEST: $\quad 222$ Guidance and Counselling teachers

MOEST: $\quad 214$ Heads of schools

MOEST: $\quad 474$ In-school peer educators trained

MGSCSS: 228 Religious and community leaders trained

MOH: $\quad 22$ Public Health Technicians trained.

The expansion of KARHP built upon the understanding gained of how to implement a multisectoral approach at the district and community levels to develop and refine processes for quickly replicating the activities in new administrative areas. This approach benefits ministries and their staff by building their capacity to integrate HIV prevention and RH information and services for adolescents into their routine work, rather than creating new sets of activities for themselves, or for nongovernment or faith-based organizations. After training, staff from each of the ministries act as the key implementers of the ARH activities. Additionally, the participation of peer educators, religious and civic leaders and parents in implementing activities ensures that while ministry staff implement the activities, all communities take part in the intervention, which enhances the acceptability of the activities.

With financial support from USAID/Kenya (through Population and PEPFAR funding), KARHP activities were scaled up to new areas within Western Province during the period May 2005 to April 2006. In this period the project:

- Introduced the overall KARHP approach by the three ministries throughout four other districts in Western Province;

- Introduced the MGSCSS and MOH components of KARHP, and the MOEST component in secondary schools only (to complement the PEPFAR-funded initiative by the Centre for British Teachers, or CfBT, ) in primary schools), in two further districts of the province;

- Created sustainable mechanisms to facilitate inter-ministerial cooperation at the provincial, district and divisional levels.

During the scale-up phase, the project reached 177,945 people throughout the province, and trained 1,951 people across the three ministries as implementers of KARHP activities:

MOEST: $\quad 662$ Guidance and Counselling teachers

MOEST: $\quad 662$ Heads of schools

MGSCSS: 255 Ministry Officials

MOH: $\quad 372$ Ministry of Health staff public health officers (all levels), clinical staff and nurses. 
During KARHP’s current “replication” phase (May 2006-May 2007), the KARHP approach has been introduced into two new Provinces, Eastern and Nyanza. In each province, the approach is being piloted, and ministerial capacity built, in two districts as preparation for expansion to the remaining districts during following years. To facilitate the widest possible coverage within the resources available, and to build capacity to implement this approach within each ministry, all relevant MGSCSS staff and all relevant MOH staff in the two districts have been trained. The MOEST has extremely high numbers of schools and staff. Experience by $\mathrm{CfBT}^{2}$ and by KARHP in Western Province demonstrated that training staff and parent representatives from one third of the primary and secondary schools in a district can effectively ensure that sufficient capacity to provide school-based HIV and RH information is built within the ministry at the district level. The MOEST can then take responsibility to ensure that this capacity is used to introduce KARHP into the remaining two-thirds of schools. Indeed in Western Province this approach proved successful, with the Provincial Education Board approving funds for expansion of KARHP into two thirds of schools not covered. Similar promises of MOEST support for expansion into schools not covered by USAID funding have been negotiated in Eastern and Nyanza provinces.

Following the lessons learned in Western Province, the following activities have been undertaken to support replication of KARHP into the two provinces:

- Revision of the training materials piloted during the OR project and further following feedback during the institutionalization phase, is on going and updated versions with more detailed information on sexual violence and FGM/C (which is prevalent in Eastern province) will be used.

- An inter-ministerial coordination mechanism has been developed at provincial and district level in both provinces that is responsible for planning all training and on-going supportive supervision.

- The management information system (MIS) is being used to collect information necessary for reporting to PEPFAR and USAID, and ministry-specific indicators have been added on request.

- Technical assistance continues to be provided to the three ministries at the central level to ensure that policies and procedures are developed for integrating adolescent-focused RH and HIV activities into their programs, and that funding for adolescent HIV and RH programs receives attention during budgetary planning, especially as transitions to sector wide approaches and budgetary support evolve. Assistance is also being provided to the districts and provinces to assist them in preparing strategies, workplans and budgets that explicitly include necessary resources.

To support the replication of KARHP in the two provinces simultaneously, FRONTIERS is taking the lead in two districts of Eastern Province, while PATH is taking the lead in two

\footnotetext{
2 Maticka-Tyndale, E. 2004. "Final Report on PSABH Evaluation in Nyanza and Rift Valley,” Primary School Action for Better Health Project, Centre for British Teachers. Nairobi: Kenya.
} 
districts of Nyanza Province. Both organizations continue to work closely at the national level to facilitate inter-ministry collaboration. Each organization has a full-time Field Coordinator based at the Provincial Headquarter of the two provinces. Although working in different provinces, the two organizations regularly and jointly review progress in both provinces to ensure smooth implementation of KARHP at all levels - national, provincial, district and divisional.

Monitoring and evaluation of program performance, documentation of lessons learned, and reporting on required PEPFAR indicators, is primarily the responsibility of FRONTIERS; review, refinement and production of all training and IEC materials is primarily the responsibility of PATH. Staff from both organizations work together at the national level to assist the three ministries to assimilate the components into their standard protocols and policies.

During this replication phase, the project has to date (May 2006 - December 2006) trained 641 ministry personnel across the three ministries in both provinces as implementers of KARHP activities:

MOEST: $\quad 45$ Provincial and District level Ministry Officials

MOEST: 121 Guidance and Counselling teachers

MOEST: 234 Heads of schools and chairpersons of School Management Committees

MGSCSS: 72 Provincial and District level Ministry Officials

MOH: $\quad 169$ Ministry of Health staff public health officers at all levels and clinical staff and nurses

\section{Implementation of KARHP}

In summary, this extended program of developing, testing, refining and scaling up a publicsector approach to addressing the RH and HIV needs of adolescents has followed four phases:

1. Operations Research: A 2⿺辶2-year phase of developing the multisectoral approach, systematically evaluating it in locations in two districts in Western Province, and obtaining agreement by all stakeholders on a final version of the approach.

2. Adaptation and institutionalization: A 20-month phase beginning with revising the multisectoral approach based on lessons learned about feasibility, acceptability, effectiveness and cost. The capacity of the three ministries to implement the revised approach was then built at the provincial and district levels, the intervention expanded throughout the original two pilot districts, and commitment at the national level that this approach would form a central component of each ministry's ARH strategy.

3. Scale-up: A 12-month phase, during which support was provided to the three ministries to extend the approach into the remaining six districts of Western Province, so that the entire province is covered, including all community-level MOH staff, all community-level MGSCSS staff, and one third of all schools. Inter-ministerial committees at several levels ensure coordination between each ministry and inter-sectoral support to jointly address ARH 
issues. Funding commitment was obtained from the province to support extension of KARHP to remaining schools.

4. Replication: A 13-month phase to introduce KARHP into two additional provinces, through building implementation capacity within the three ministries at provincial level, and supporting pilot introduction in two districts in each province. FRONTIERS and PATH are responsible for one province each and have joint responsibilities for program strengthening at the national level; each organization is also responsible for specific technical areas to sustain and strengthen the program.

\section{A brief outline of the key components of KARHP is given below.}

\section{Training}

KARHP maintains the cascade training and capacity building approach that was developed in the OR project and refined during the institutionalization phase. In this approach, national and provincial level officials from the three ministries are recruited and trained as "master trainers" to train and supervise representatives from their ministry at the district and divisional levels, who can function as the "core trainers." The core trainers then train the zonal heads, teachers, Social Development Assistants, Public Health Technicians, clinical staff and other personnel within each ministry. This cascade-training model is strengthened at every level by the presence of a master trainer or a core trainer from the higher level; where possible a KARHP Field Coordinator will also attend for quality assurance.

\section{Inter-ministerial coordination and advocacy}

These quarterly meetings, at the provincial and district levels, are attended by one representative from each ministry. The meetings serve several purposes: increasing information-sharing across ministries; facilitating the integration of adolescent RH and HIV activities into ministry calendars; enhancing monitoring and supervision; strengthening data collection activities; and mapping and coordinating the activities of nongovernment organization and other stakeholders. Once the initial one or two quarterly meetings have been held, the committees will organize for themselves how best to continue meeting every quarter.

\section{Management Information System}

Within the schools, the guidance and counseling teachers submit brief reports of activities undertaken monthly to the TAC tutors, and this information is collected by the KARHP Field Assistants in each province. For the MGSCSS, reports of activities are prepared by the social development associates (SDA), who submit them monthly for collection by the Field Assistants. For the $\mathrm{MOH}$, the public health officers (PHOs) prepare monthly reports and submit them to their District PHO for collection by the Field Assistants. The Field Assistants then enter the data collected into an electronic database in the two field offices, and the FRONTIERS Program Officer processes and analyses them in Nairobi. The monthly reports are collated into quarterly reports to be shared during the quarterly inter-ministerial meetings. Regular reports are also sent to the ministry representatives at national level, and the MIS generates data for reporting to USAID/PEPFAR. 


\section{Revision and production of materials}

Training guides for each of the different training sessions have been produced that can be used by the master and core trainers when leading the various training sessions. Staff from PATH undertake this activity and also develop the training materials needed, as well as completing any revisions to the core training curriculum (see Appendix 1) and accompanying communication materials. This curriculum has been designed primarily for use by teachers with schoolchildren, and has been adapted into versions for primary and secondary schools. As demonstrated in the OR study and scale up phase, however, it has proved useful also among out of school youth, as well as during community meetings and by health personnel in clinics and during community outreach.

\section{Technical support at national level}

FRONTIERS and PATH program officers in Nairobi continue to provide technical assistance to staff at the three ministries. The technical support helps the staff to ensure that policies and procedures are developed for integrating adolescent-focused RH and HIV activities into their programs, and that funding for adolescent HIV and RH programs receives attention during budgetary planning. Support is also being provided to strengthen the National Inter-ministry Committee to further institutionalize the program and oversee monitoring and supervision in Western, Nyanza and Eastern Provinces. 


\section{Appendix 1: Outline of KARHP's Curriculum}

\section{GROWING UP}

\section{Module 1: Adolescent Development}

Topic 1: $\quad$ Adolescence

Topic 2: $\quad$ Reproductive System - Male and Female

Topic 3: $\quad$ Myths and Misconceptions about Reproduction

Topic 4: $\quad$ Life Skills: Setting Goals

Topic 5: $\quad$ Life Skills: Values

Module 2: Relationships

Topic 6: $\quad$ Types of Relationships

Topic 7: $\quad$ Life Skills: Communication (Verbal, Nonverbal Communication and Listening)

Topic 8: $\quad$ Friendship

Topic 9: $\quad$ Boy/Girl Relationships

Topic 10: $\quad$ Love and Infatuation

Module 3: Gender and Human Sexuality

Topic 11: Introduction to Gender

Topic 12: $\quad$ Gender Stereotypes

Topic 13: $\quad$ Sexuality and Behaviour

\section{HEALTHY ADOLESCENTS}

\section{Module 4: Preventive Behaviours}

Topic 14: Life Skills: Self-Esteem

Topic 15: $\quad$ Life Skills: Assertiveness Skills

Topic 16: Life Skills: Decision-Making

Topic 17: Abstinence

Topic 18: $\quad$ Condom Use

Topic 19: Other Methods of Contraception

\section{Module 5: Teenage Pregnancy and Abortion}

Topic 20: $\quad$ Parenthood

Topic 21: Teenage Pregnancy

Topic 22: $\quad$ Unsafe Abortion

Topic 23: $\quad$ Sexual Exploitation, Rape and Gender Violence

\section{Module 6: HIV and AIDS}

Topic 24: $\quad$ HIV and AIDS

Topic 25: $\quad$ VCT

Topic 26: $\quad$ Care and Support 
Module 7: Other Sexually Transmitted Diseases

Topic 27: $\quad$ Sexually Transmitted Diseases

Topic 28: $\quad$ Facts and Myths - STIs/ HIV/AIDS

Module 8: Drug Abuse

Topic 29: $\quad$ Drug Abuse

Topic 30: $\quad$ Life Skills: Resisting Peer Pressure

Facilitators' Resources

Resource 1: Facilitation Techniques

Resource 2: Guidance and Counselling

Resource 3: Condoms

Resource 4: Other ways to prevent Pregnancy

Resource 5: $\quad$ Students with Special needs

\section{The following publications on the Kenya Adolescent Reproductive Health Project can be found on our website:}

Askew, Ian and Humphres Evelia. 2007. "Mainstreaming and scaling up the Kenya Adolescent Reproductive Health Project,” FRONTIERS Report. Nairobi: Population Council.

"Kenya: Multisectoral engagement increases support for youth reproductive health," FRONTIERS OR Summary no. 65. Washington, DC: Population Council, 2007.

"Tuko Pamoja [We are Together]: Adolescent reproductive health and life skills curriculum." 2006. Nairobi: PATH and the Population Council.

"Tuko Pamoja [We are Together]: A guide for talking with young people about their reproductive health." 2005. Nairobi: PATH and the Population Council.

Askew, Ian, Jane Chege, Carolyne Njue, and Samson Radeny. 2004. “A multi-sectoral approach to providing reproductive health information and services to young people in Western Kenya: The Kenya adolescent reproductive health project," FRONTIERS Final Report. Washington, DC: Population Council.

"Kenya: Communities support adolescent reproductive health education, " FRONTIERS OR Summary no. 33. Washington, DC: Population Council, 2003.

"Kenya update: FRONTIERS adolescent reproductive health project," FRONTIERS Project Update no. 1. Nairobi: Population Council, 2001.

See: http://www.popcouncil.org/frontiers/projects/afr/Kenya_RHYouthRI.htm

or e-mail frontiers@pcdc.org 